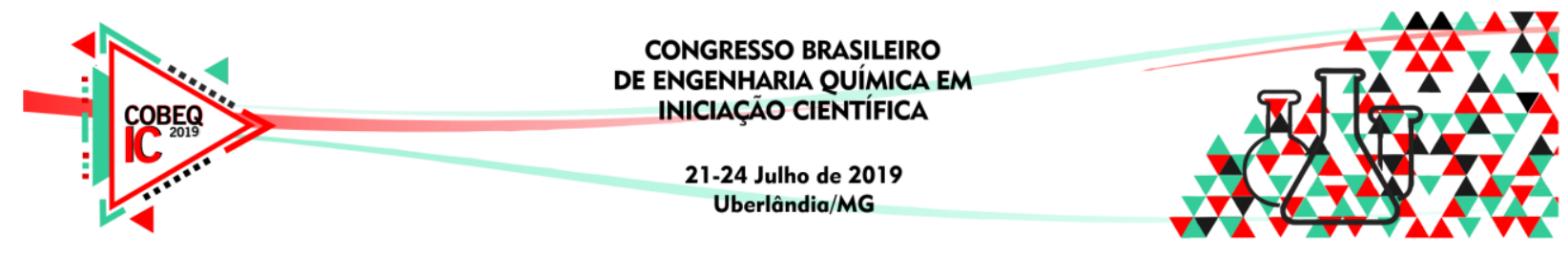

\title{
ANÁLISE DO DESEMPENHO DE UMA NOVA LINHAGEM DE Candida pseudointermedia DIANTE DE CARBOIDRATOS E INIBIDORES ENCONTRADOS NA PRODUÇÃO DE ETANOL DE SEGUNDA GERAÇÃO
}

\author{
L. DEOTI ${ }^{*}$, A. GIEHL ${ }^{1}$, A. C. LUCARONI ${ }^{1}$, L. M. MILANI ${ }^{1}$ e S. L. ALVES JR. ${ }^{1}$ \\ ${ }^{1}$ Universidade Federal da Fronteira Sul, Campus Chapecó, \\ Laboratório de Bioquímica e Genética \\ *E-mail para contato: leticiadeoti@gmail.com
}

\begin{abstract}
RESUMO - A carência de microrganismos capazes de fermentar xilose e celobiose e de tolerar inibidores ácidos carboxílicos (ácido acético e ácido fórmico), dificulta a produção de etanol $2 \mathrm{G}$. Visando encontrar uma levedura tolerante aos inibidores mencionados e eficiente na fermentação de glicose, xilose e celobiose, a cepa selvagem Candida pseudointermedia UFFS-CE-3.6 teve seus perfis de crescimento celular, consumo de açúcares e produção de etanol avaliados em diferentes meios de cultura. Os resultados obtidos demonstram que a levedura logrou êxito com crescimento nos três carboidratos, no entanto, obteve expressiva produção de etanol apenas na presença da hexose. O consumo de celobiose foi o mais afetado pelos inibidores, de modo que as células não foram capazes de crescer nessa fonte de carbono diante da concentração intermediária dos ácidos a que foram submetidas as células $\left(1,8 \mathrm{~g} \mathrm{~L}^{-1}\right.$ de ácido acético e $0,3 \mathrm{~g} \mathrm{~L}$ ${ }^{1}$ de ácido fórmico). Em contrapartida, em glicose e xilose as células só foram completamente inibidas nas concentrações mais altas dos dois inibidores $\left(3,6 \mathrm{~g} \mathrm{~L}^{-1}\right.$ e $0,6 \mathrm{~g} \mathrm{~L}^{-1}$ de ácido acético e ácido fórmico, respectivamente). De todo modo, o aumento gradual dos inibidores sempre retardou o início do consumo de açúcares e estendeu a fase lag para os crescimentos celulares. Assim, este estudo demonstra que a espécie avaliada possui grau intermediário de tolerância a inibidores, porém dispõe de todas as enzimas necessárias para garantir o metabolismo de xilose e celobiose.
\end{abstract}

\section{INTRODUÇÃO}

A expansão da frota de transportes brasileira tem ocasionado, nos últimos anos, um aumento considerável do consumo de biocombustíveis veicular no Brasil. O etanol de segunda geração $(2 \mathrm{G})$ pode ser obtido a partir de resíduos de biomassa lignocelulósica oriundos da produção do etanol de primeira geração. Este é obtido pelo processamento primário da biomassa, enquanto aquele é oriundo do bagaço e da palha da cana, assim como de materiais em decomposição, produzindo energia limpa e renovável e diminuindo a quantidade de resíduos do ambiente. 


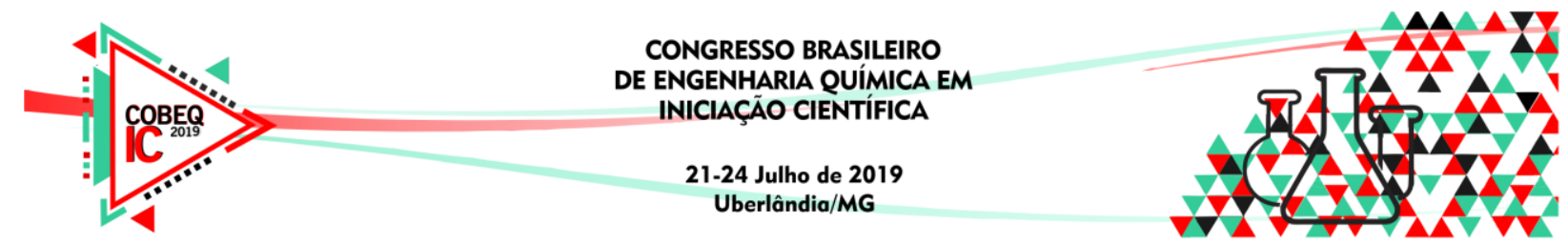

$\mathrm{O}$ etanol $2 \mathrm{G}$ é produto da fermentação, realizada por leveduras, dos carboidratos que constituem a biomassa lignocelulósica, composta basicamente por celulose, hemicelulose e lignina (Rubin, 2008). Para o acesso das enzimas aos polissacarídeos ser facilitado, é necessário separar a lignina da hemicelulose e da celulose, processo conhecido como prétratamento lignocelulósico. Durante esta sequência, compostos tóxicos chamados de inibidores são gerados, prejudicando o crescimento e a fermentação microbiana. Jönsson e Martín (2016) mostram que a maioria dos inibidores derivados da lignocelulose se forma durante o pré-tratamento, quando hemiceluloses e/ou lignina são solubilizados e degradados. Segundo Klinke et al. (2004), os inibidores são fatores limitantes na viabilidade de conversões biotecnológicas de lignocelulose para a produção de etanol.

A levedura Saccharomyces cerevisiae é a principal responsável pela produção de etanol de primeira geração, devido a suas adaptações às condições industriais de fermentação alcoólica. No entanto, ela é incapaz de fermentar tanto a xilose (Stambuk et al., 2008), que é o segundo açúcar mais abundante nos hidrolisados lignocelulósicos, quanto a celobiose (Lee et al., 2017), fato que limita seu uso na produção de etanol 2G. Sendo assim, o principal desafio a ser superado é encontrar novas leveduras capazes de fermentar os açúcares presentes no hidrolisado, como a glicose, xilose e celobiose, além de tolerar os inibidores advindos dos processos que antecedem a fermentação, como ácido acético e ácido fórmico.

Leveduras selvagens têm sido amplamente avaliadas com o objetivo de conhecer a capacidade de fermentação de xilose e celobiose, assim como a tolerância a inibidores ácidos. Guamán-Burneo et al. (2015) demonstrou recentemente que a espécie Candida pseudointermedia é capaz de consumir xilose. Portanto, o uso de novas leveduras pode contribuir com a indústria de etanol, sendo utilizadas tanto isoladamente quanto expressando seus genes em $S$. cerevisiae.

Este trabalho avaliou a tolerância de uma levedura selvagem de $C$. pseudointermedia, linhagem UFFS-CE-3.6, em meios com glicose, xilose e celobiose sob diferentes concentrações de ácidos fracos (ácido acético e ácido fórmico). O estudo do comportamento dessa levedura é de essencial importância visando sua possível aplicabilidade na produção de etanol de segunda geração.

\section{MATERIAIS E MÉTODOS}

\subsection{Isolamento e Identificação das Leveduras}

A levedura UFFS-CE-3.6 foi isolada a partir de amostras de matéria vegetal em decomposição coletadas nas matas da Universidade Federal da Fronteira Sul - Campus Chapecó, em uma região de Mata Atlântica do Sul do Brasil, localizada no Oeste de Santa Catarina. Seu isolamento e sua identificação taxonômica foram realizados conforme Bazoti et al. (2017).

\subsection{Crescimento Celular, Consumo de Açúcares e Produção de Etanol}

A análise dos perfis de crescimento celular iniciou com um pré-cultivo por 48 horas em $10 \mathrm{~mL}$ de meio rico, contendo $1 \%$ de extrato de levedura, $2 \%$ de peptona e $2 \%$ de glicose. As 


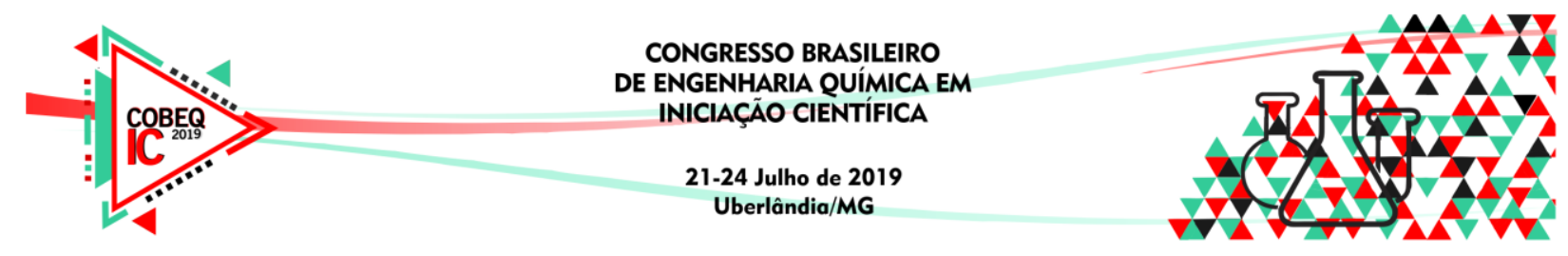

células pré-crescidas foram posteriormente inoculadas em frascos Erlenmeyer com meio mínimo YNB (1/100 do volume final), contendo $0,67 \%$ de base nitrogenada e $2 \%$ de glicose, xilose ou celobiose como fontes de carboidrato. Os meios foram ajustados em $\mathrm{pH} 5,0 \mathrm{e}$ esterilizados em autoclave a $120^{\circ} \mathrm{C}$ por 20 minutos. Os frascos foram incubados sob agitação periódica de $145 \mathrm{rpm}$ a $25^{\circ} \mathrm{C}$.

Para avaliar o grau de tolerância das células aos diferentes inibidores de fermentação, foram adicionadas concentrações crescentes de ácido acético e ácido fórmico aos meios de cultura, de forma independente. $\mathrm{O}$ ácido acético foi utilizado com concentrações de $0 \mathrm{~g} \mathrm{~L}^{-1}$ como controle, $0,6 \mathrm{~g} \mathrm{~L}^{-1}, 1,8 \mathrm{~g} \mathrm{~L}^{-1}$ e $3,6 \mathrm{~g} \mathrm{~L}^{-1}$, enquanto o ácido fórmico, por possuir propriedades altamente tóxicas, foi utilizado em menores concentrações de $0 \mathrm{~g} \mathrm{~L}^{-1}, 0,1 \mathrm{~g} \mathrm{~L}^{-1}$, $0,3 \mathrm{~g} \mathrm{~L}^{-1}$ e $0,6 \mathrm{gL}^{-1}$. Em tempos previamente determinados (8 coletas durante 48 horas), as amostras de cada cultivo celular foram coletadas e passaram pela verificação do crescimento celular em espectrofotômetro, com absorbância a 570 nm (DO570nm).

O consumo de açúcares e a produção de etanol foram avaliados com amostras retiradas dos meios de cultura em tempos pré-determinados e centrifugadas por três minutos a $5.000 \mathrm{~g}$. Os sobrenadantes das amostras foram filtrados para posterior análise em HPLC (fase móvel 5 $\mathrm{mM}$ H2SO4, 50 ${ }^{\circ}$, fluxo de 0,6 mL min ${ }^{-1}$ em coluna Aminex HPX-87H, Bio-Rad, e detecção por índice de refração RID-10, Shimadzu).

\section{RESULTADOS E DISCUSSÃO}

Para avaliar a tolerância da levedura UFFS-CE-3.6 aos inibidores ácido acético e ácido fórmico e seu metabolismo celular diante dos principais açúcares encontrados em hidrolisados lignocelulósicos, comparou-se o crescimento celular da linhagem em diferentes concentrações de ambos os ácidos em meios com glicose, xilose ou celobiose, além de seu perfil de consumo dos referidos carboidratos e a produção de etanol realizada pelas suas células.

A linhagem foi capaz de crescer em meios contendo alternadamente as três fontes de carbono, mas os efeitos de inibição sobre o crescimento celular foram diretamente proporcionais às concentrações dos inibidores (Figuras 1-A e 1-D, 2-A e 2-D, 3-A e 3-D): quanto maior a concentração de ácido, maior a fase lag antes do início do crescimento exponencial. A mesma relação se observou também nos perfis de consumo dos carboidratos analisados (Figuras 1-B e 1-E, 2-B e 2-E, 3-B e 3-E).

As taxas de consumo de açúcar foram sempre maiores e os crescimentos foram sempre inferiores em meios com glicose (Figura 1), os únicos em que se observou produção de etanol $\left(\sim 9 \mathrm{~g} \mathrm{~L}^{-1}\right)$. Isso corrobora os dados de Duval et al. (2010), que demonstram que, quando açúcares são consumidos lentamente, o metabolismo das leveduras é essencialmente respiratório, gerando maior biomassa celular, como observado nos crescimentos da UFFSCE-3.6 em xilose e celobiose (Figuras 2 e 3). Em outras palavras, a levedura, em condições contendo apenas um desses dois carboidratos como fonte de carbono, metabolizou-os através da respiração e não da fermentação alcoólica, por isso houve maior crescimento celular e ausência da produção de etanol nos diferentes meios. De fato, recentemente foram encontradas diferentes leveduras com capacidade de consumo de xilose, mas em suas células esse açúcar foi completamente oxidado a $\mathrm{CO}_{2}$ pela respiração celular ou apenas convertido a xilitol (Sena et al., 2017). 

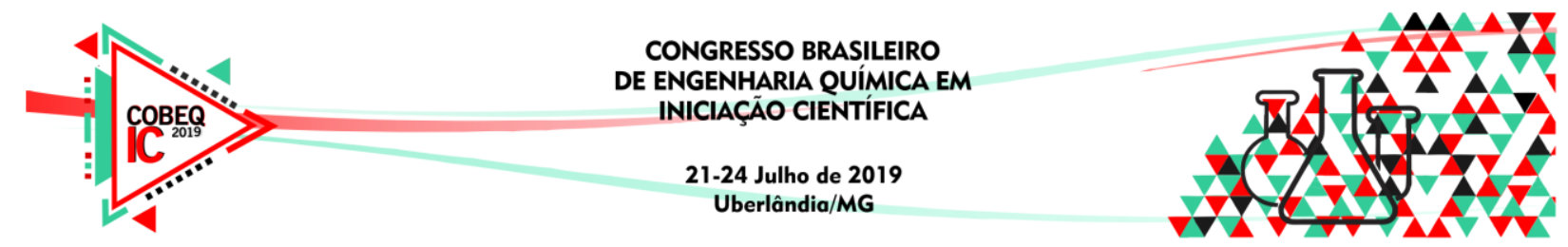

Figura 1 - Perfis de crescimento celular (A e D), consumo de carboidrato (B e E) e produção de etanol (C e F) da levedura UFFS-CE-3.6 em meios com $2 \%$ de glicose como fonte de carbono. Os meios continham ainda, alternadamente, $0(\boldsymbol{\Delta}), 0,6(\bullet), 1,8(\boldsymbol{\square})$ e 3,6 (४) $\mathrm{gL}^{-1} \mathrm{de}$ ácido acético $\left(\mathrm{A}, \mathrm{B}\right.$ e C) ou $0(\triangle), 0,1(\circ), 0,3(\square)$ e $0,6(\diamond) \mathrm{gL}^{-1}$ de ácido fórmico (D, E e F).

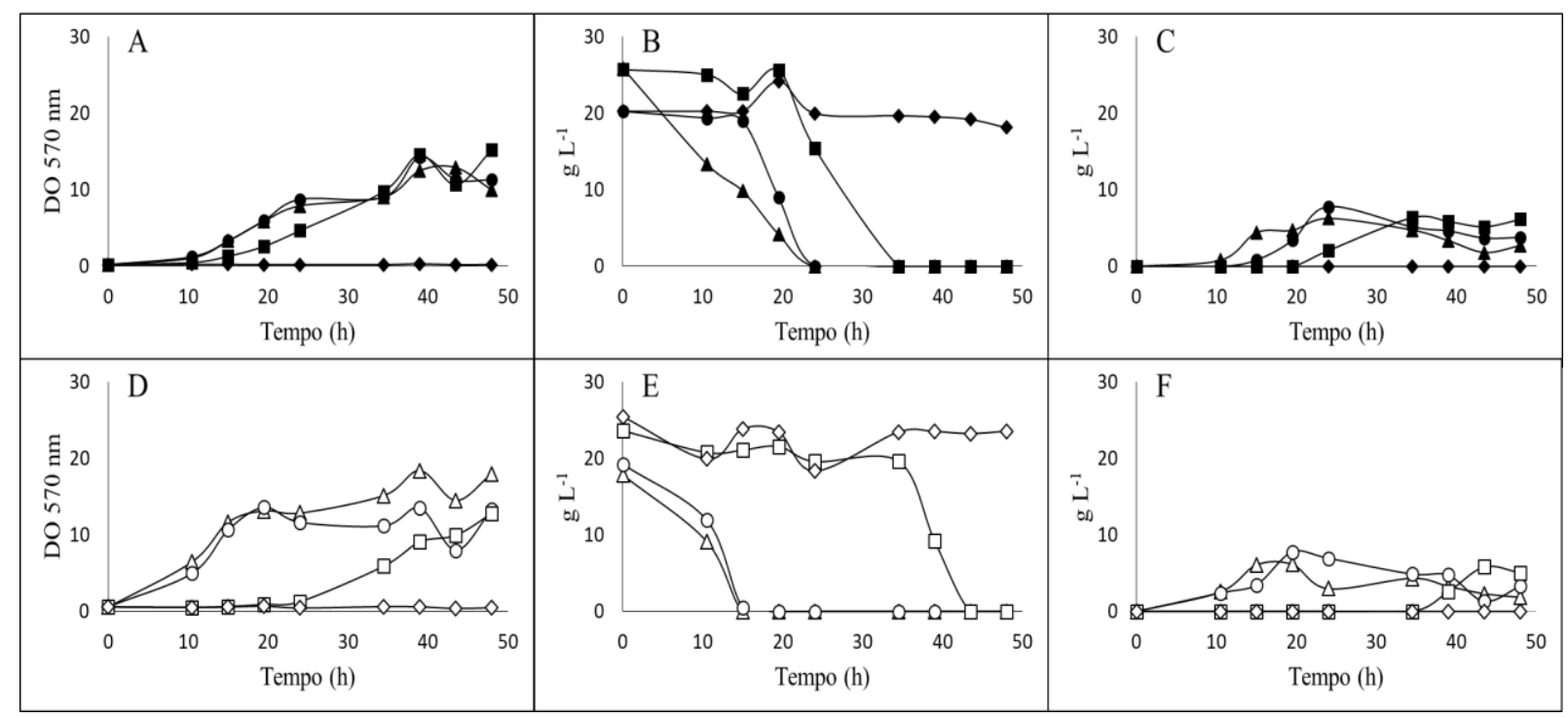

Figura 2 - Perfis de crescimento celular (A e D), consumo de carboidrato (B e E) e produção de etanol (C e F) da levedura UFFS-CE-3.6 em meios com $2 \%$ de xilose como fonte de carbono. Os meios continham ainda, alternadamente, $0(\boldsymbol{\Delta}), 0,6(\bullet), 1,8(\boldsymbol{\square})$ e 3,6 (४) $\mathrm{gL}^{-1} \mathrm{de}$ ácido acético (A, B e C) ou $0(\triangle), 0,1(\circ), 0,3(\square)$ e $0,6(\diamond) \mathrm{gL}^{-1}$ de ácido fórmico (D, E e F).

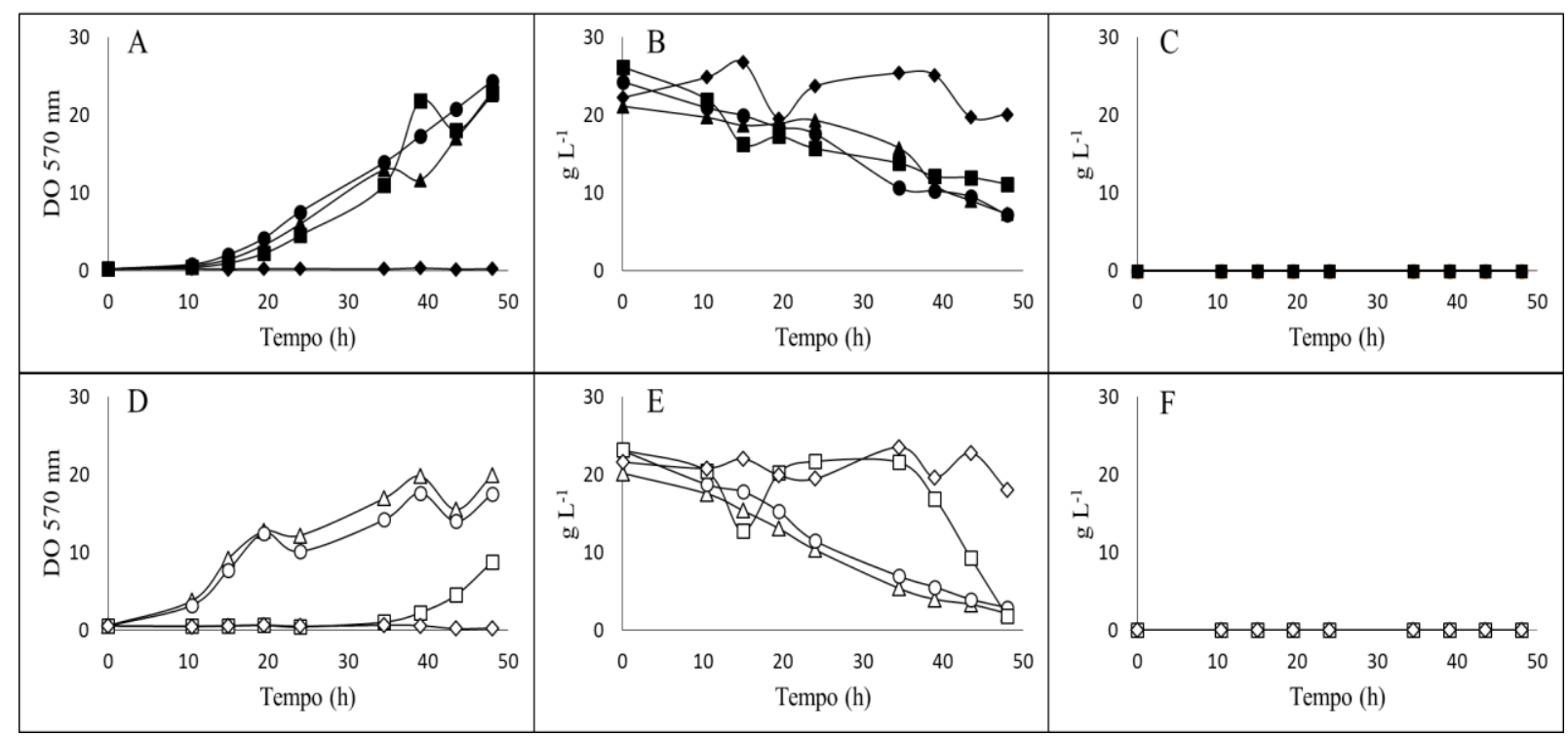




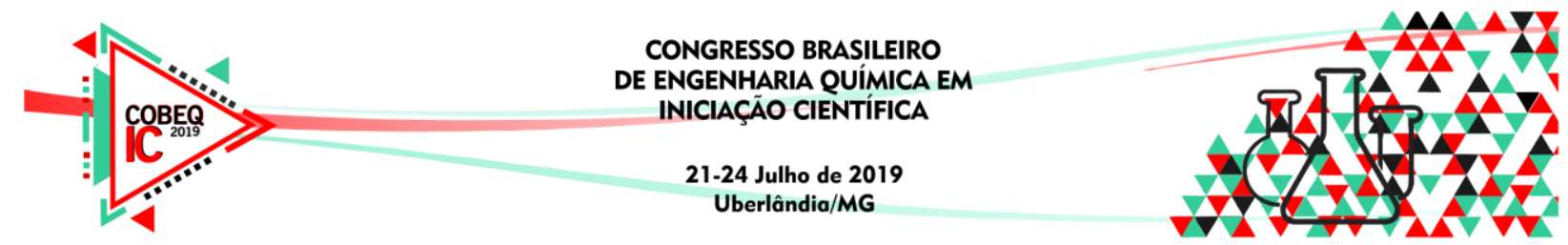

Figura 3 - Perfis de crescimento celular (A e D), consumo de carboidrato (B e E) e produção de etanol ( $\mathrm{C}$ e F) da levedura UFFS-CE-3.6 em meios com $2 \%$ de celobiose como fonte de carbono. Os meios continham ainda, alternadamente, $0(\boldsymbol{\Delta}), 0,6(\bullet), 1,8(\boldsymbol{\square})$ e 3,6 (•) $\mathrm{gL}^{-1} \mathrm{de}$ ácido acético $\left(\mathrm{A}, \mathrm{B}\right.$ e C) ou $0(\triangle), 0,1(\circ), 0,3(\square)$ e $0,6(\diamond) \mathrm{gL}^{-1}$ de ácido fórmico (D, E e F).

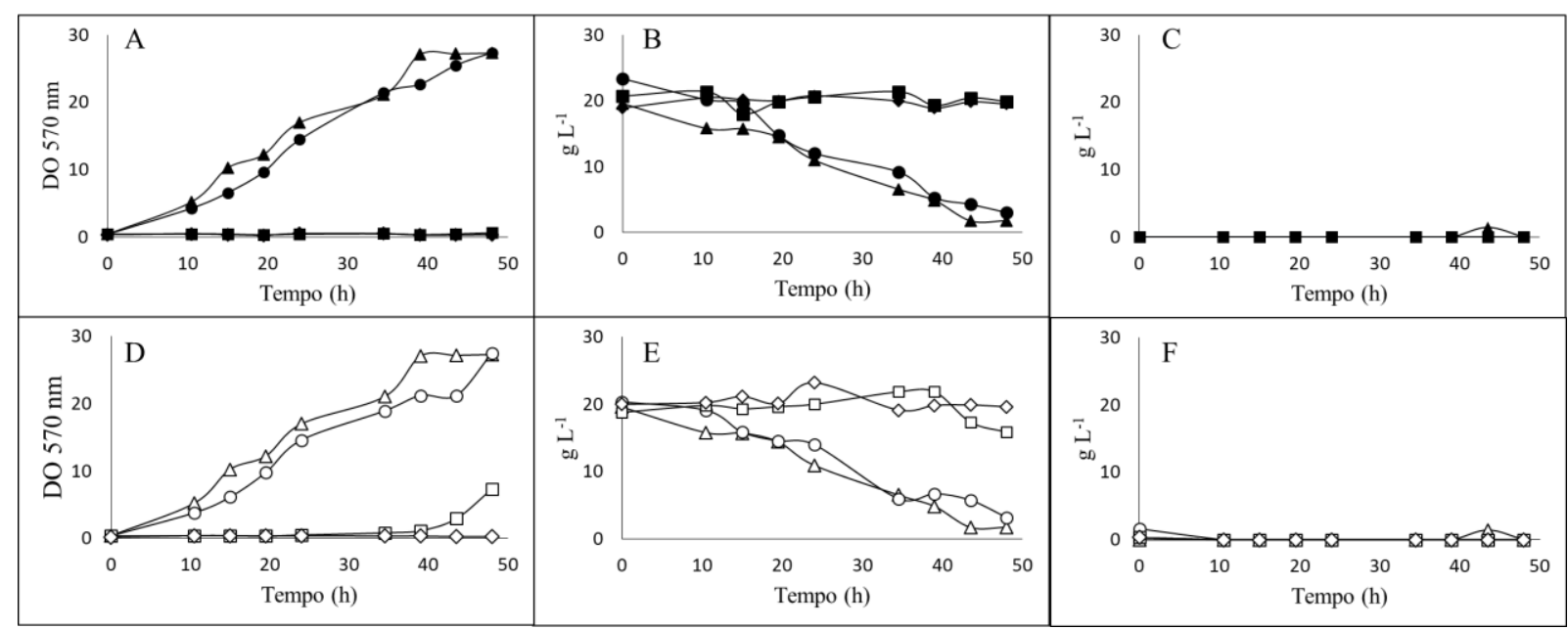

A inibição foi mais pronunciada quando as células se encontravam metabolizando a celobiose (Figura 3), haja vista a ausência total de consumo de açúcar e crescimento celular na concentração intermediária de inibidores $\left(1,8 \mathrm{~g} \mathrm{~L}^{-1}\right.$ de ácido acético e $0,3 \mathrm{~g} \mathrm{~L}^{-1}$ de ácido fórmico). Já nos meios com glicose (Figura 1) ou xilose (Figura 2), a levedura só foi completamente inibida nas maiores concentrações testadas dos ácidos carboxílicos em questão (3,6 $\mathrm{g} \mathrm{L}^{-1}$ de ácido acético e $0,6 \mathrm{~g} \mathrm{~L}^{-1}$ de ácido fórmico). Esses são dados são similares aos que Du et al. (2019) observaram recentemente para a levedura Spathaspora passalidarum, espécie também encontrada na Mata Atlântica (Cadete e Rosa, 2018).

\section{CONCLUSÃO}

A levedura $C$. pseudointermedia UFFS-CE-3.6 tolerou os inibidores ácido acético e ácido fórmico em diferentes concentrações nas três fontes de carbono testadas: glicose, xilose e celobiose. Esta espécie, embora não tenha fermentado a xilose e a celobiose, pode ser uma potencial fornecedora de genes a serem expressos em leveduras já empregadas na produção de etanol atualmente produzido a partir de material lignocelulósico, assim como sua resistência e eficiência podem ser melhoradas através de engenharia evolutiva. Portanto, os estudos realizados relacionados a levedura UFFS-CE-3.6 são de fundamental importância para a otimização do etanol $2 \mathrm{G}$.

\section{REFERÊNCIAS}

BAZOTI, S. F.; GOLUNSKI, S.; SIQUEIRA, D. P.; SCAPINI, T.; BARRILLI, E. T.; MAYER, D. A.; BARROS, K. O.; ROSA, C. A.; STAMBUKE, B. U.; ALVES JR, S. L.; VALÉRIO, A.; OLIVEIRA, D.; TREICHEL, H. Second-generation ethanol from non-detoxified sugarcane hydrolysate by a rotting wood isolated yeast strain. Bioresour Technol, v. 244, p. 582-587, 2017. 


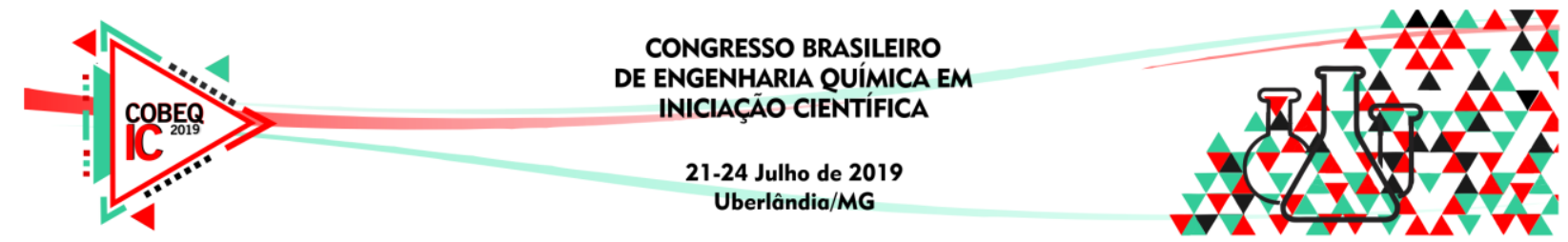

CADETE, R. M.; ROSA, C. A. The yeasts of the genus Spathaspora: potential candidates for second-generation biofuel production. Yeast, v. 35, p. 191-199, 2018.

DU, C., LI, Y., ZHAO, X., PEI, X., YUAN, W., BAI, F., JIANG, Y. The production of ethanol from lignocellulosic biomass by Kluyveromyces marxianus CICC 1727-5 and Spathaspora passalidarum ATCC MYA-4345. Appl Microbiol Biotechnol, v. 103, p. 2845-2855, 2019.

DUVAL, E. H.; ALVES Jr., S. L.; DUNN, B.; SHERLOCK, G.; STAMBUK, B. U. Microarray karyotyping of maltose-fermenting Saccharomyces yeasts with differing maltotriose utilization profiles reveals copy 52 number variation in genes involved in maltose and maltotriose utilization. Journal of Applied Microbiology, v.109, p.248-259, 2010 .

GUAMÁN-BURNEO, M. C.; DUSSÁN, K. J.; CADETE, R. M.; CHEAB, M. A.; PORTERO, P.; CARVAJAL-BARRIGA, E. J.; SILVA, S. S.; ROSA, C. A. Xylitol production by yeasts isolated from rotting wood in the Galápagos Islands, Ecuador, and description of Cyberlindnera galapagoensis f.a., sp. nov. Antonie Van Leeuwenhoek, v. 108, p. 919-931, 2015.

JÖNSSON, L. J.; ALRIKSSON, B.; NILVEBRANT, N. Bioconversion of lignocellulose: inhibitors and detoxification. Biotechnology for Biofuels, v. 6, p. 1-16, 2013.

JÖNSSON, L. J.; MARTÍN, C. Pretreatment of lignocellulose: Formation of inhibitory byproducts and strategies for minimizing their effects. Bioresource Technology, v. 199, p. 102-112, 2016.

KLINKE, H. B.; THOMSEN, A. B.; AHRING, B. K. Inhibition of ethanol-producing yeast and bacteria by degradation products produced during pre-treatment of biomass. Applied Microbiology and Biotechnology, v. 66, p. 10-26, 2004.

LEE, W. H.; JIN, Y. S. Evaluation of ethanol production activity by engineered Saccharomyces cerevisiae fermenting cellobiose through the phosphorolytic pathway in simultaneous saccharification and fermentation of cellulose. Journal of Microbiology and Biotechnology, v. 27, p. 1649-1656, 2017.

RUBIN, E. M. Genomics of cellulosic biofuels. Nature, v. 454, p. 841-845, 2008.

SENA, L. M., MORAIS, C. G., LOPES, M. R., SANTOS, R. O., UETANABARO, A. P., MORAIS, P. B., VITAL, M. J., DE MORAIS, M. A. JR., LACHANCE, M. A., ROSA, C. A. D-Xylose fermentation, xylitol production and xylanase activities by seven new species of Sugiyamaella. Antonie Van Leeuwenhoek, v. 110, p. 53-67, 2017.

STAMBUK, B. U.; ELEUTHERIO, E. C. A.; FLOREZ-PARDO, L. M.; SOUTO-MAIOR, A. M.; BON, E. P. S. Brazilian potential for biomass ethanol: challenge of using hexose and pentose co-fermenting yeast strains. Journal of Scientific and Industrial Research, v. 67, p. 918-926, 2008. 